\title{
Highly variable gastric emptying in patients with insulin dependent diabetes mellitus
}

\author{
T V Nowak, C P Johnson, J H Kalbfleisch, A M Roza, C M Wood, J P Weisbruch, \\ K H Soergel
}

Indiana University

Medical Center,

Department of

Medicine, Division of

Gastroenterology,

Indianapolis, Indiana,

USA

T V Nowak

Departments of

Medicine and

Transplant Surgery,

Medical College of

Wisconsin, Milwaukee,

Wisconsin, USA

C P Johnson

A M Roza

$C M$ Wood

J P Weisbruch

K H Soergel

Division of Biometry and Medical

Computing, Section of

Medical Education,

East Tennessee State

University, Johnson

City, TN 37601, USA

J H Kalbfleisch

Correspondence to:

Dr T V Nowak, (111G)

Richard L Roudebush VA

Medical Center, Department
of Medicine, Division of

Gastroenterology, 1481 West

Tenth Street, Indianapolis,

IN 46202-2803, USA.

Accepted for publication

1 November 1994

\begin{abstract}
Some diabetic patients - particularly those with nausea and vomiting - frequently have evidence of delayed gastric emptying while other diabetic patients may in fact exhibit accelerated gastric emptying. Whether the presence or absence of symptoms of upper gastrointestinal dysfunction correlated with objective measures of gastric emptying in insulin dependent diabetic subjects was investigated. Twenty one insulin dependent diabetic patients underwent a solid phase gastric emptying scintiscan using in vivo labelled chicken liver. Thirteen patients had symptoms suggestive of gastrointestinal dysfunction (nausea, vomiting, early satiety, or constipation), while eight patients had no gastrointestinal symptoms. Eleven patients had orthostatic hypotension. All patients had been diabetic since childhood or adolescence. As a group, the diabetic patients showed a half time $\left(T_{50}\right)$ of gastric emptying (mean (SD) $150.0 \mathrm{~min}(163.7)$ that was not significantly different from that of 12 healthy control subjects $(148 \cdot 1$ min (62.4)). Those diabetic patients without gastrointestinal symptoms and without orthostatic hypotension, however, showed a gastric emptying half time $(\mathbf{7 0} \cdot 1 \mathrm{~min}$ (41.6)) that was significantly faster than that of the control subjects. Conversely, those diabetic patients with nausea, vomiting, and early satiety (or early satiety alone) showed $T_{50}$ values that were significantly greater than those of the diabetic patients without these symptoms. No correlation was found between the $T_{50}$ value and the duration of diabetes, the fasting blood glucose at the time of study, or the respiratory variation in heart rate (E:I ratio). These observations indicate that highly variable rates of gastric emptying occur in insulin dependent diabetic patients, and that accelerated gastric emptying may occur in diabetic patients who have no symptoms of gastrointestinal dysfunction.
\end{abstract}

(Gut 1995; 37: 23-29)

Keywords: Gastric emptying, autonomic neuropathy.

Patients with diabetes mellitus not infrequently complain of nausea, vomiting, early satiety, diarrhoea, constipation, or faecal incontinence. The exact prevalence of these gastrointestinal symptoms in a diabetic population has not been extensively examined. In one study, however, $76 \%$ of diabetic patients attending an outpatient clinic complained of one or more gastrointestinal symptoms. ${ }^{1}$ Nearly a third of these patients had episodes of nausea and vomiting. The true prevalence of gastrointestinal dysfunction in diabetes mellitus is probably underestimated, as some diabetic patients may not manifest symptoms of nausea, vomiting, or early satiety, yet may experience unexplained episodes of hypoglycaemia as a result of abnormally delayed gastric emptying. ${ }^{2-4}$.

The pathophysiology of gastric dysfunction in diabetes mellitus - known as diabetic gastropathy - is obscure. Typically, these patients manifest symptoms of gastric retention while radiographic, endoscopic, and nuclear scintigraphic studies show evidence of delayed gastric emptying of both solid and liquid meals. However, this particular syndrome - known as gastroparesis diabeticorum - contrasts with occasional studies which show that some diabetic patients (both type I and type II) may show accelerated gastric emptying of a liquid meal. ${ }^{5-10}$ Hence, the effect of diabetes mellitus on gastric emptying in humans is confusing. The purpose of this investigation was to examine the influence of diabetes mellitus on gastric emptying of a solid meal in two groups of insulin dependent diabetic subjects, namely those who had and those who did not have symptoms of upper gastrointestinal dysfunction.

\section{Methods}

Twenty one insulin dependent diabetic subjects volunteered for the study. None were taking any medications known to affect gastrointestinal motility and non had undergone gastric or intestinal surgery. The presence of renal failure, or treatment with haemodialysis or chronic ambulatory peritoneal dialysis did not disqualify any patient from entering the study. On the day of the study, each patient underwent a history and physical examination that was performed by one of the authors (TVN), measurement of the fasting blood sugar, evaluation of orthostatic changes in pulse and blood pressure, and an electrocardiogram to measure the respiratory variation in heart rate during full expiration and full inspiration (E:I ratio). Each patient also underwent a brief sensory neurological examination that included evaluation of peripheral sharp versus dull discrimination and perception of soft touch and vibration.

Each patient was specifically questioned by the interviewer (TVN) about upper gastrointestinal symptoms such as nausea, vomiting, 
early satiety, and lower gastrointestinal symptoms such as diarrhoea and constipation. Nausea was defined as the sensation of epigastric or abdominal queasiness that typically precedes frank vomiting. Vomiting was defined as the forceful ejection of gastric contents through the mouth. During questioning careful distinction was made on the part of the interviewer to distinguish vomiting from regurgitation. Early satiety was defined as the premature sensation of postprandial abdominal fullness. Symptoms such as diarrhoea or constipation was considered present if the patient subjectively felt that he or she had an abnormal evacuation pattern, that the abnormal evacuation pattern had been present for more than six months, and that the current evacuation pattern represented a change from that which was present from when the patient felt 'healthy'.

Diarrhoea was defined as the passage of several watery evacuations per day while constipation was defined as the passage of infrequent stools (less than several times per week) or evacuations that were difficult to pass or required the use of laxatives or enemas. Informed consent was obtained from all participants. The protocol was approved by the Human Research Review Committee of the Medical College of Wisconsin.

GASTRIC EMPTYING PROTOCOL

After an overnight fast each subject ingested a beef stew meal containing $1 \mathrm{~cm}^{3}$ cubes of chicken liver that had been labelled in vivo with ${ }^{99} \mathrm{mTc}$-sulphur colloid as previously described. ${ }^{11}$ Each meal was approximately 225 $\mathrm{kcal}$ and contained approximately 100-125 $\mathrm{mCi}$ of ${ }^{99} \mathrm{mTc}$. Each subject ingested the test meal with one cup of tap water within five minutes or less. Except for imaging purposes, subjects were seated upright during the study. Successive one minute anterior and posterior images were collected immediately after completion of meal ingestion (time 0 ) and then at 10 minute intervals with the subjects standing apposed to the collimator. All studies of diabetic patients were continued until less than $40 \%$ of the starting count remained in the region of interest (ROI) or until three hours had elapsed. A General Electric Maxi II $\gamma$-camera (General Electric Company, Medical Systems Division, Milwaukee, WI) was used with a low energy, high sensitivity, parallel hole collimator at a $25 \%$ window setting. This was connected to a Star computer (General Electric Company) for data collection and processing. A ROI corresponding to the stomach was selected. After correction for radioactive decay, each count rate over the ROI was converted to per cent of the initial (or near maximum) count rate recorded - that is, the percentage remaining in the ROI. Results of the solid phase gastric emptying study obtained in the diabetic subjects were compared to those established at the Medical College of Wisconsin of an identical solid in vivo labelled chicken liver meal. These normative data were based upon studies performed in
12 healthy, asymptomatic male and female volunteers and published previously by the authors. ${ }^{11}$

\section{ANCILLARY STUDIES}

Each diabetic subject underwent (1) measurement of the orthostatic changes in blood pressure after rising from a supine to a standing position, and (2) measurement of the inspiratory-expiratory variation in heart rate. To determine the orthostatic cardiovascular response to standing, each subject was allowed to remain supine for at least five minutes to insure a stable baseline blood pressure. ${ }^{12}$ The pulse and arm cuff blood pressures were then recorded and measurements were repeated in the same arm within one minute after the subject had been asked to stand. Orthostatic hypotension was defined as a drop of at least $20 \mathrm{~mm} \mathrm{Hg}$ in systolic or diastolic blood pressure upon standing.

Measurement of the respiratory variation in heart rate was performed in the supine position with a conventional electrocardiogram machine. Each subject was allowed a 5-10 minute supine rest period before beginning the recording. The subject was carefully instructed to exhale fully over five seconds, to inhale fully over the next five seconds, and to repeat this cycle six times over the next minute. Subjects practised the manoeuvre several times before recording. Each expiratory-inspiratory cycle was timed and the patient was verbally instructed when to begin each inspiration and expiration. Electrocardiogram recordings were obtained in leads I, AVR, and AVF. The R-R interval was visually analysed. Each $\mathrm{E}: \mathrm{I}$ ratio is the longest $R-R$ interval during expiration divided by the shortest $R-R$ interval during the successive inspiration. The $E$ :I ratio value assigned to each patient was the mean of six E:I ratios calculated during the one minute recording. ${ }^{13}$ The E:I ratios obtained for each patient were compared to published E:I ratios of normal healthy individuals. ${ }^{14}$

\section{DATA ANALYSIS}

To describe gastric emptying of each meal, the values representing the percentage of meal remaining $(\mathrm{Y})$ at each measurement time point (X) were analysed with the non-linear power exponential regression model ${ }^{15}$ using the SAS software package ${ }^{16}$ :

$$
\mathrm{Y}=(100 \%) \cdot 2^{-\left[\frac{\mathrm{X}}{\mathrm{A}}\right]^{\mathrm{B}}}
$$

The model parameter $\mathrm{A}$ is the time at which $50 \%$ emptying has occurred (or $\mathrm{T}_{50}$ ) and $\mathrm{B}$ is a parameter that determines the shape of the emptying curve. Large values of B result in a curve that has a very rapid descent once that emptying commences. $\mathbf{R}^{2}$ for non-linear models was used to document how well the model describes each data set. ${ }^{15}$ Figure 1 displays two diabetic patient data sets and the power exponential curve that were fit to each.

The gastric emptying trends of the diabetic patients and the healthy subjects were 
TABLE I Characteristics of the diabetic patients studied

\begin{tabular}{|c|c|c|c|c|c|c|c|c|c|c|}
\hline Patient & Sex & $\begin{array}{l}\text { Age } \\
\text { (y) }\end{array}$ & $\begin{array}{l}\text { Upper } \\
\text { gastrointestinal } \\
\text { symptoms }\end{array}$ & $\begin{array}{l}\text { Time } \\
\text { to half } \\
\text { empty } \\
\text { (min) }\end{array}$ & $\begin{array}{l}\text { Model } \\
\text { fit } \\
\left(R^{2}\right)\end{array}$ & $\begin{array}{l}\text { Orthostatic } \\
\text { hypotension }\end{array}$ & $\begin{array}{l}\text { Peripheral } \\
\text { neuropathy }\end{array}$ & Dialysis & $F B S$ & $\begin{array}{l}\text { Duration } \\
\text { of } \\
\text { diabetes } \\
(y)\end{array}$ \\
\hline KA & $M$ & 28 & No & 11 & 0.999 & No & No & Haemo & $24 \cdot 8$ & 21 \\
\hline LB & $M$ & 31 & No & 176 & 0.965 & Yes & Yes & Haemo & $18 \cdot 1$ & 19 \\
\hline CB & $\mathrm{F}$ & 39 & No & 139 & 0.915 & Yes & Yes & CAPD & 3.9 & 15 \\
\hline CB & M & 37 & No & 129 & 0.983 & No & No & None & $4 \cdot 4$ & 27 \\
\hline $\mathrm{HB}$ & M & 31 & No & 37 & 0.982 & No & Yes & Haemo & $10 \cdot 0$ & 18 \\
\hline BB & $\mathrm{F}$ & 26 & No & 90 & 0.955 & No & No & None $^{\star}$ & $10 \cdot 5$ & 20 \\
\hline IG & $\mathrm{F}$ & 33 & No & 136 & 0.963 & Yes & Yes & CAPD & $12 \cdot 3$ & 17 \\
\hline MH & $\mathrm{F}$ & 42 & Yes & 673 & 0.695 & Yes & Yes & CAPD & $8 \cdot 7$ & 29 \\
\hline JJ & $\mathrm{F}$ & 36 & No & 80 & 0.978 & No & No & Haemo & 4.9 & 23 \\
\hline SP & $M$ & 37 & No & 31 & 0.976 & No & Yes & None & - & 25 \\
\hline $\mathrm{KR}$ & M & 40 & No & 116 & 0.940 & No & Yes & None ${ }^{\star}$ & $3 \cdot 0$ & 27 \\
\hline MV & $\mathrm{F}$ & 33 & No & 68 & 0.945 & No & Yes & CAPD & $6 \cdot 4$ & 25 \\
\hline NM & M & 41 & Yes & 212 & 0.943 & Yes & Yes & None & 16.9 & 24 \\
\hline JB & M & 27 & Yes & 68 & 0.963 & Yes & Yes & None & $5 \cdot 2$ & 15 \\
\hline RW & M & 33 & Yes & 23 & 0.985 & Yes & Yes & Haemo & $15 \cdot 0$ & 23 \\
\hline $\mathrm{KB}$ & $\mathrm{F}$ & 28 & Yes & 539 & 0.906 & No & Yes & Haemo & $15 \cdot 3$ & 15 \\
\hline JO & M & 36 & Yes & 79 & 0.982 & No & Yes & Haemo & $4 \cdot 6$ & 23 \\
\hline $\mathrm{CB}$ & $\mathrm{F}$ & 35 & Yes & 175 & 0.968 & Yes & Yes & Haemo & 6.9 & 22 \\
\hline MT & $M$ & 28 & Yes & 207 & 0.978 & Yes & Yes & Haemo & $11 \cdot 1$ & 16 \\
\hline $\mathrm{KF}$ & $\mathrm{F}$ & 39 & No & 112 & 0.990 & Yes & Yes & Haemo & $12 \cdot 3$ & 34 \\
\hline SS & M & 32 & No & 50 & 0.987 & Yes & Yes & Haemo & $5 \cdot 0$ & 22 \\
\hline
\end{tabular}

Haemo=haemodialysis; $\mathrm{CAPD}=$ chronic ambulatory peritoneal dialysis; FBS=fasting blood glucose $(\mathrm{mmol} / \mathrm{l})$.

$\star$ Status after kidney transplant.

compared by evaluating differences in group means (SD) for the A and B values. Bartlett's test for homogeneity of variances and the F-max test were used to compare SDs. In the light of significant differences between group SDs for A, three group means were compared with Welch's test (one way analysis of variance assuming heterogeneous variances) and multiple pairwise comparisons of two group means were performed with the $t$ test (assuming unequal group variances) and levels of significance were adjusted according to Bonferroni's method. ${ }^{17}$ In addition, within the diabetic group the $A$ and $B$ values were analysed with a multifactor analysis of variance using upper gastrointestinal symptoms, lower gastrointestinal symptoms, orthostatic hypotension, and peripheral neuropathy as factors (the GLM procedure in SAS-PC employing type III sum of squares). This analysis assesses the level of significance of each factor while accounting for the possible join effects of the other factors on the variable (A or B) being analysed. Probability levels of 0.05 or smaller were used as a guide for statistical significance.

\section{Results}

Table I shows the characteristics of the 21 diabetic patients who were studied. There were nine women and 12 men who ranged in age from 21 to 42 years (mean: $32 \cdot 2$ years). The mean duration of diabetes mellitus was 21.8 years (range 15-34 years). All patients had been diabetic since childhood or adolescence and had diabetic retinopathy. One patient had normal renal function and three were preuraemic. Two had undergone successful renal transplantation for diabetic nephropathy, while 14 were undergoing chronic haemodialysis or chronic ambulatory peritoneal dialysis.

The power exponential emptying curves fit to diabetic patients and the healthy control subjects are shown in Figures 1 and 2. In a similar display, the more variable gastric emptying trends observed in the diabetic patients are illustrated in Figure 3 . The summary statistics for the healthy subjects and diabetic patients are given in Table II. Comparison of the group mean responses for the $50 \%$ emptying time (A) and shape (B) show no statistically significant differences when the entire diabetic group is compared to the healthy subject group. This suggests that the mean emptying pattern of the two groups is very similar. However, as shown in Figure 3, there is a marked variation in the emptying patterns of diabetic patients. The SDs for the emptying curve parameters (A and B) of the diabetic group are significantly different from the corresponding standard deviations of the healthy subject group (Table II). Figure 3 also shows that there is an apparent subgroup of diabetic patients that shows rapid gastric emptying, at least at a rate more rapid than that shown by the healthy subject group. A smaller number of diabetic patients show very slow or delayed gastric emptying. Therefore, gastric emptying trends were further analysed to determine if any of the symptom characteristics in the diabetic patients could be statistically associated with either rapid or delayed gastric emptying.

Table III shows the statistical summary of gastric emptying analyses when the patients are classified by the presence or absence of (1) upper gastrointestinal symptoms, (2) orthosta-

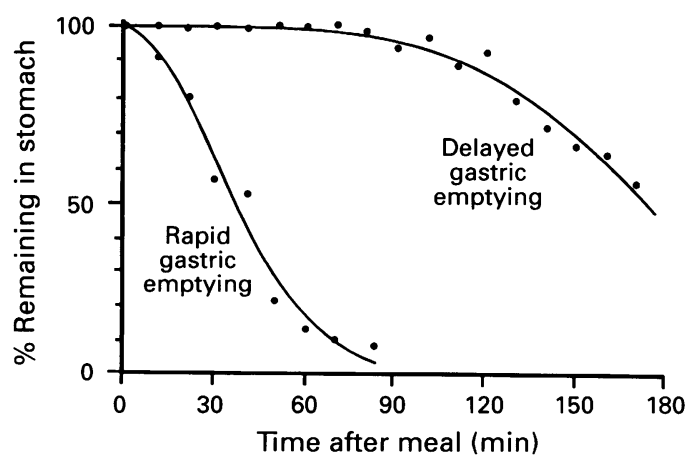

Figure 1: Illustration of the power exponential curve fits for diabetic patients with a rapid gastric emptying pattern $(A=36.8$ minutes and $B=1.85)$ and a delayed emptying pattern $(A=174 \cdot 5$ minutes and $B=4 \cdot 36)$. 


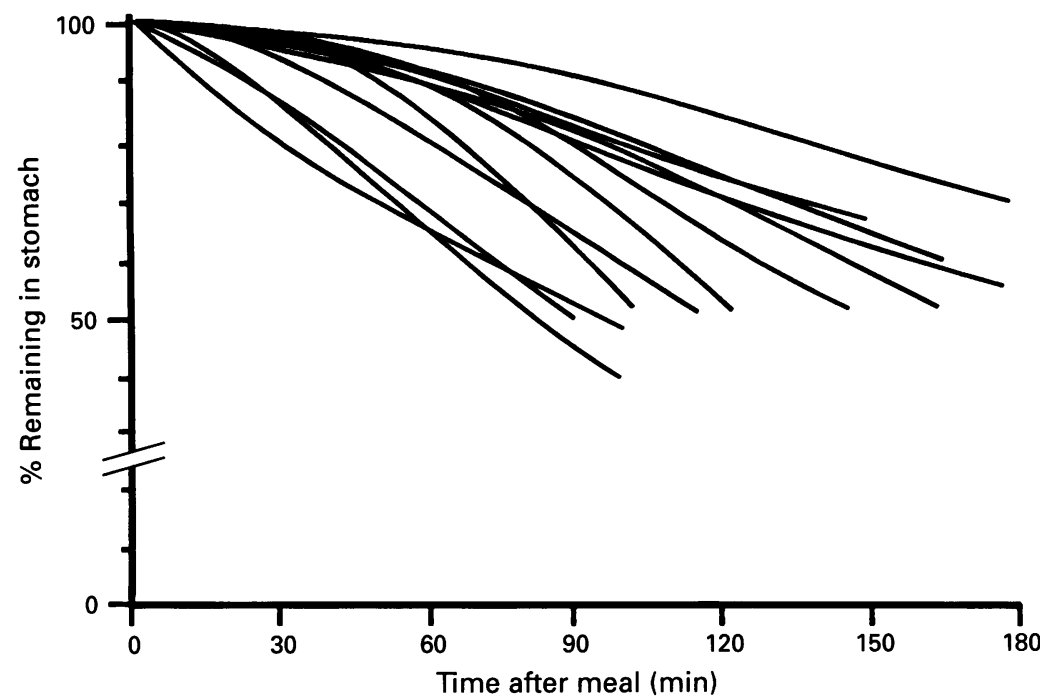

Figure 2: Illustration of the power exponential regression curves for gastric emptying in the 12 healthy subjects. Curves are drawn to depict the time at which half emptying has been achieved. The summary statistics for this group are given in Tables II and III.

tic hypotension, (3) peripheral neuropathy, (4) early satiety, and (5) lower gastrointestinal symptoms. The absence or presence of gastrointestinal symptoms was used to categorise further the diabetic patients into those with 'no symptoms' and those with 'some symptoms'. As shown in Table III, the patients in the 'no symptoms' category $\left(\mathrm{S}^{-}\right.$in Fig 4$)$ had a $50 \%$ emptying time $(70 \cdot 1$ minutes) that differed significantly from the mean $50 \%$ emptying time of the healthy subjects (148.1 minutes). The 13 patients in the 'some symptoms' category ( $\mathrm{S}^{+}$in Figure 4$)$ had a mean $50 \%$ emptying time ( $199 \cdot 1$ minutes) that is indicative of delayed emptying but not significantly different than the $50 \%$ emptying time seen in the healthy subjects.

Examination of individual symptom categories (Table III) shows that absence of upper gastrointestinal symptoms and absence of lower gastrointestinal symptoms relate to subgroups of diabetic patients that have significantly lower mean 50\% gastric emptying times than the healthy control subjects. The

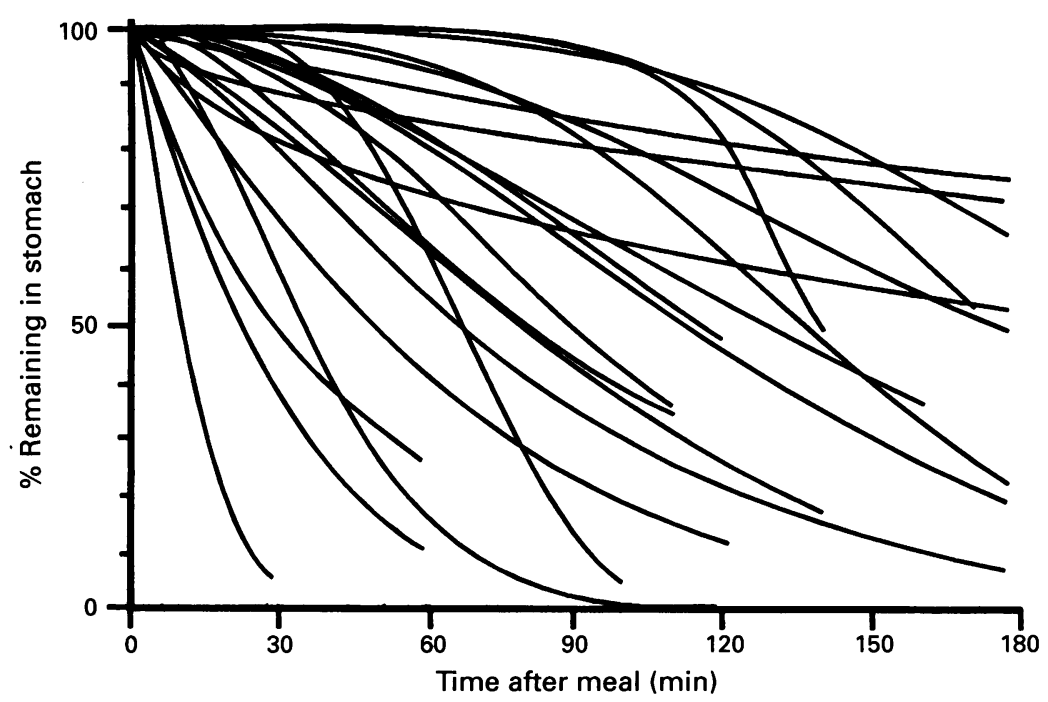

Figure 3: Power exponential regression gastric emptying curves from the 21 diabetic patients. Curves end when the measuring session was terminated (which was limited to 180 minutes). The summary statistics for this group are given in Tables II and III. gastric emptying shape coefficient (B) is not significantly related to the symptom categories shown in Table III. Figure 5 shows the individual E:I ratios with respect to each subject's age using published results of normal healthy subjects. ${ }^{14}$ Nineteen of the 21 diabetic patients showed an abnormal E:I ratio (below the 95th centile) and one patient showed an E:I ratio that was marginally abnormal (lower 90th centile). The E:I ratio provided no basis for discrimination among the patients with reference to presence or absence of symptoms, or rates of gastric emptying.

Other study variables that were assessed for a relation with the coefficients of gastric emptying curves are shown in Table IV. Fasting blood glucose concentrations taken before the gastric emptying study did not correlate significantly with gastric emptying (A or B). Change in systolic and diastolic blood pressures during the assessment for orthostatic hypotension did not correlate significantly with gastric emptying. Age and duration of diabetes were not significantly correlated with the $50 \%$ emptying time (A). However, the duration of diabetes was significantly (negatively) correlated with the gastric emptying shape coefficient (B). This relation implies that a longer duration of diabetes is associated with a lower value of B that is a slower rate of gastric emptying.

\section{Discussion}

In contrast to the delay in gastric emptying that has been characteristically described in patients with diabetic gastropathy, the present study shows that some diabetic patients have accelerated, rather that retarded, gastric emptying. Delayed gastric emptying, known as diabetic gastroparesis, is typically encountered in patients who have symptoms of disordered upper gastrointestinal dysfunction - that is, nausea, vomiting, pyrosis, or early satiety. These patients often have evidence of the secondary complications of diabetes such as retinopathy, nephropathy, vasculopathy, and autonomic and peripheral neuropathy. In contrast, the diabetic patients with accelerated gastric emptying evaluated in the present study had no symptoms of upper or lower gastrointestinal dysfunction and no evidence of orthostatic hypotension. This study also shows that the rate of emptying is slower for patients with a longer duration of diabetes mellitus.

The pathophysiology of diabetes mellitus and gastric motor function in humans is obscure. It is appreciated that there are three main controls that regulate gastric emptying. These are: (1) the influence of extrinsic and intrinsic nervous systems, (2) the influence of gastrointestinal hormones, and (3) the intrinsic contractile properties of visceral smooth muscle itself. Studies in human diabetic subjects show that gastric muscle retains its ability to contract in response to excitatory cholinergic agonists. ${ }^{18}$ Therefore, the intrinsic contractile properties of smooth muscle seem to be intact in the diabetic state. Whether hormonal controls regulating gastrointestinal motility are altered in diabetes mellitus is unknown. 
TABLE II Comparison of gastric emptying parameters between healthy subjects and diabetic patients

\begin{tabular}{lcll}
\hline $\begin{array}{l}\text { Gastric emptying } \\
\text { parameter }\end{array}$ & $\begin{array}{l}\text { Healthy subjects } \\
(n=12)\end{array}$ & $\begin{array}{l}\text { Diabetic patients } \\
(n=21)\end{array}$ & $\begin{array}{l}\text { Level of } \\
\text { significance }\end{array}$ \\
\hline $\begin{array}{l}\text { 50\% Emptying time (A) } \\
\text { Mean }\end{array}$ & $148 \cdot 1$ & $150 \cdot 0$ & $\mathrm{NS}$ \\
Median & $132 \cdot 8$ & 112.1 & $\mathrm{NS}$ \\
(SD) & $(62 \cdot 4)$ & $(163 \cdot 7)$ & $\mathrm{p}<0.01$ \\
$\begin{array}{l}\text { Shape of emptying curve (B) } \\
\text { Mean }\end{array}$ & 1.74 & $2 \cdot 13$ & $\mathrm{NS}$ \\
Median & 1.59 & 1.67 & $\mathrm{NS}$ \\
(SD) & $(0.47)$ & $(1.62)$ & $\mathrm{p}<0.01$ \\
\hline
\end{tabular}

$A$ and $B$ are the parameters of the power exponential regression model that describes gastric emptying. The time to half empty is the A parameter and B defines the shape of the emptying pattern. NS= not significantly different.

Most clinical observations in human diabetes support the notion that defects in vagal innervation are responsible for the gastric motility abnormalities in diabetes mellitus. Sham feeding studies - in which gastric acid secretion is stimulated via vagal pathways show that diabetic patients have an appreciably attenuated gastric acid secretory response to a sham fed meal. ${ }^{19}$ However, these same subjects show a normal acid secretory response to pentagastrin, a hormone which acts directly on the parietal cell. This indicates that the endorgan secretory function of the parietal cell is intact, but that the defect is in the vagal controls which modulate that response. A recent light and electron microscopic study showed no morphological changes in the vagus nerve or gastric myenteric plexus from patients with diabetes mellitus. ${ }^{20}$ However, histochemical studies were not performed. Likewise, it has become recently appreciated that neurons in the central motor nucleus and sensory nucleus (tractus solitarius) of the vagus nerve regulate gastric motor function. ${ }^{2122}$ Whether dysfunction of either of these brainstem nuclei is a determinant of the gastric motor abnormalities in the diabetic state is unknown.

Acute experimental diabetes of 30-60 days duration in rodents has been shown to be associated with accelerated gastric emptying of a nutrient meal. ${ }^{23} 24$ This phenomenon seems to be specific for the carbohydrate component of the meal, as diabetes enhances gastric emptying of glucose but not of fat. ${ }^{23}$ Accelerated

TABLE III Comparison of gastric emptying parameters between healthy subjects and diabetic patient subgroups

\begin{tabular}{|c|c|c|c|c|}
\hline & $\begin{array}{l}\text { Sub } \\
\text { group }\end{array}$ & No & $\begin{array}{l}50 \% \text { Emptying } \\
\text { time }(A) \\
(\text { mean }(S D))\end{array}$ & $\begin{array}{l}\text { Shape of emptying } \\
\text { curve (B) } \\
\text { (mean (SD)) }\end{array}$ \\
\hline Healthy subjects & & 12 & $148 \cdot 1(62 \cdot 4)$ & $1.74(0.47)$ \\
\hline Some symptoms & & 13 & $199 \cdot 1(191.9)^{\star}+$ & $2.48(2.00)^{\star}+$ \\
\hline No symptoms & & 8 & $70 \cdot 1(41 \cdot 6)^{\star}+$ & $1.58(0.35)$ \\
\hline \multirow{2}{*}{ Upper gastrointestinal symptoms } & + & 8 & $246.9(234.7)^{\star} \dagger \ddagger$ & $2.05(1.56)^{\star}$ \\
\hline & - & 13 & $90 \cdot 3(49 \cdot 5)^{\star} \ddagger$ & $2 \cdot 19(1 \cdot 77)^{\star}$ \\
\hline \multirow{2}{*}{ Orthostatic hypotension } & + & 11 & $179 \cdot 1(175 \cdot 3)^{\star}$ & $2.70(2.09)^{\star} \dagger$ \\
\hline & - & 10 & $117.9(152.5)^{\star}$ & $1.51(0.39)$ \\
\hline \multirow{2}{*}{ Peripheral neuropathy } & + & 16 & $166.5(183 \cdot 1)^{\star} \dagger$ & $2.13(1.76)^{\star}$ \\
\hline & - & 5 & $97.0(60.5)$ & $2 \cdot 17(1.25)$ \\
\hline \multirow{2}{*}{ Early satiety } & + & 7 & $262 \cdot 1(245 \cdot 7)^{\star} \dagger$ & $1.79(2.57)^{\star}$ \\
\hline & & 14 & $93.9(56.9)^{\star}$ & $2 \cdot 81(0.80)^{\star}$ \\
\hline \multirow[t]{2}{*}{ Lower gastrointestinal symptoms } & + & $\begin{array}{r}14 \\
6\end{array}$ & $296.0(245 \cdot 0)^{\star} \ddagger$ & $3.05(2.67)^{\star}$ \\
\hline & - & 15 & $91 \cdot 7(64 \cdot 3)^{\star} \ddagger$ & $1.77(0.89)^{\star}$ \\
\hline
\end{tabular}

$+/-$ indicates diabetic subgroups with/without corresponding symptoms.

* Statistically different than healthy subjects, $p<0.05$; †statistically different than other diabetic subgroups, $p<0.05$; $\ddagger$ statistically different than ' + ' diabetic subgroup, $p<0.05$, with the multifactorial analysis of variance F-test (type III) in the SAS-PC GLM procedure.

'No symptoms' is absence of upper and lower gastrointestinal symptoms, early satiety and no orthostatic hypotension. 'Some symptoms' includes the other patients who have one or more of the aforementioned symptoms.

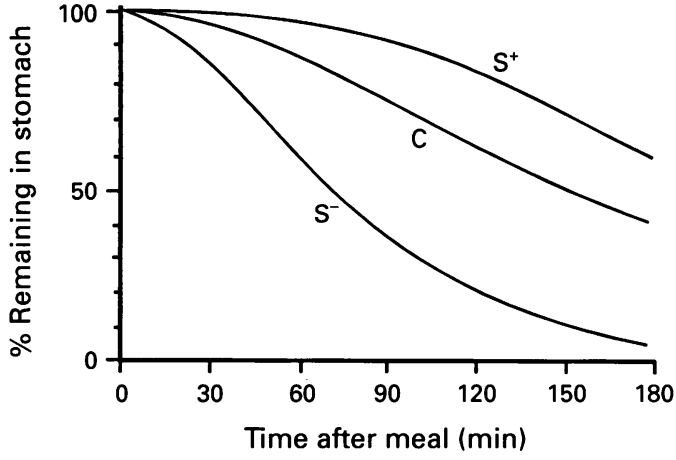

Figure 4: Mean regression gastric emptying curve for the healthy subjects (C), diabetic patients with gastrointestinal symptoms or orthostatic hypotension $\left(S^{+}\right)$and diabetic patients without gastrointestinal symptoms and without orthostatic hypotension $\left(S^{-}\right)$. Mean values of $A$ and $B$ from Table III were used to determine the mean curves in the figure.

gastric emptying is seen in genetically diabetic $\mathrm{BB} / \mathrm{W}_{\text {or }}$ rats as well as streptozotocin treated diabetic animals, a phenomenon which indicates that accelerated gastric emptying is a consequence of the diabetic state rather than a non-specific neurotoxic effect of streptozotocin. ${ }^{25}$ In addition, restoration of euglycaemia with insulin treatment or pancreas transplantation returns the rate of gastric emptying to normal. Studies in rodents also suggest that vagal factors operate in producing accelerated gastric emptying. Experiments in non-diabetic rodents showed that selective destruction of vagal afferent C-fibres by perineural application of the sensory neurotoxin capsaicin produces accelerated gastric emptying. ${ }^{26} 27$ This suggests that the rapid gastric emptying seen in diabetic rodents may be due to dysfunction of vagal afferent C-fibres. Thorough investigations of the neurochemistry,

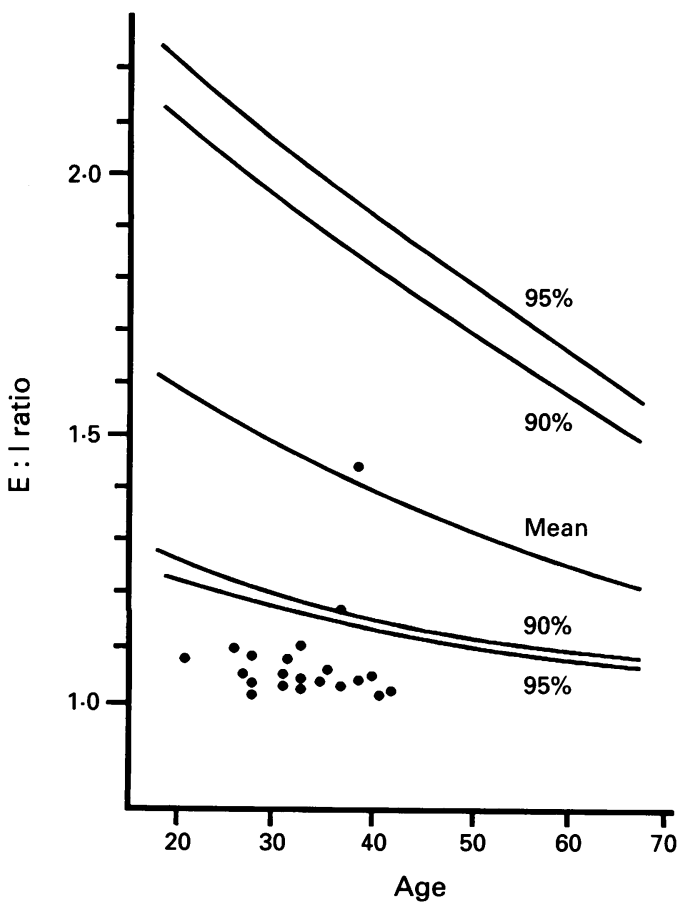

Figure 5: Relationship between the E:I ratio for each patient and respective age. Nineteen of the 21 patients studied had heart rate (E:I) ratios below the 95th centile shown by the normal subjects. Normal ranges are adapted from data published by Smith et al. ${ }^{14}$ 
TABLE IV Correlation of gastric emptying parameters with study variables in the diabetic patients

\begin{tabular}{lll}
\hline Study variable & $50 \%$ Emptying time $(A)$ & Shape of emptying curve $(B)$ \\
\hline Age (y) & $\mathrm{r}=0.213 \mathrm{p}=0.29$ & $\mathrm{r}=-0.033 \mathrm{p}=0.89$ \\
Duration of diabetes $(\mathrm{y})$ & $\mathrm{r}=0.028 \mathrm{p}=0.90$ & $\mathrm{r}=-0.482 \mathrm{p}=0.03$ \\
Fasting blood glucose $(\mathrm{mmol} / 1)$ & $\mathrm{r}=0.073 \mathrm{p}=0.77$ & $\mathrm{r}=-0.376 \mathrm{p}=0.13$ \\
Systolic BP change $(\mathrm{mm} \mathrm{Hg})^{\star}$ & $\mathrm{r}=-0.402 \mathrm{p}=0.07$ & $\mathrm{r}=-0.123 \mathrm{p}=0.59$ \\
Diastolic BP change $(\mathrm{mm} \mathrm{Hg})^{\star}$ & $\mathrm{r}=-0.124 \mathrm{p}=0.59$ & $\mathrm{r}=-0.120 \mathrm{p}=0.60$
\end{tabular}

The linear correlation coefficient between either A or B and a study variable is indicated by $r$. ${ }^{\star}$ Measured in order to check for orthostatic hypotension.

physiology, and morphology of the rodent vagus nerve in acute experimental diabetes mellitus are lacking. However, such a consideration is plausible, based on recent observations of impaired vagal $\mathrm{Na}^{+}-\mathrm{K}^{+}$-ATPase activity in rodents with acute streptozotocin induced diabetes. ${ }^{28}$

Several published investigations indicate that renal failure itself has no influence on gastric emptying. ${ }^{29-34}$ However, most of these studies were performed in uraemic, non-diabetic populations. Hence, the influence of uraemia on gastric emptying in a diabetic population has not been extensively examined. One study that investigated liquid gastric emptying in five renal failure patients (three of whom complained of nausea) found that uraemia had little influence on the rate of emptying. ${ }^{29}$ These observations agree with the results of our investigation in which no association was found between the gastric emptying half time and whether the patients were undergoing haemodialysis, chronic ambulatory peritoneal dialysis, or had normal renal function. In fact, both the longest and shortest gastric emptying half times were found in patients undergoing chronic haemodialysis. Nevertheless, most of the diabetic patients examined had renal dysfunction and were undergoing some form of dialysis. Hence, a conclusive statement regarding the impact of renal failure of gastric emptying cannot be made from the results of the present investigation.

Nearly all $(n=19)$ patients in the study had cardiovascular autonomic neuropathy evidenced by an abnormal respiratory variation in the heart rate (E:I ratio). Eleven of the patients had orthostatic hypotension as well. Two subjects who had a normal, albeit borderline, E:I ratio showed evidence of mild sensory peripheral neuropathy on physical examination. The near omnipresence of autonomic disturbances is consistent with the notion that neurogenic factors are responsible for the accelerated gastric emptying seen in these patients.

It is appreciated that an abnormal respiratory variation in heart rate can be detected in both type I and type II diabetic patients as early as 24 months after the diagnosis of diabetes mellitus has been established. ${ }^{35}$ The loss in respiratory variability in heart rate has been generally felt to be due to damage to the cardiac vagal parasympathetic nerve fibres, since atropine (a cholinergic muscarinic antagonist) abolishes $R-R$ variation in normal subjects. ${ }^{36}$ However, $\beta$ agonists also decrease the $\mathbf{R}-\mathbf{R}$ variation, which indicates that sympathetic nervous tone is also impaired. ${ }^{37}$
Orthostatic hypotension in diabetic patients is generally attributed to abnormalities in the sympathetic nervous system. ${ }^{13}$ Hence, it seems reasonable to conclude that all the patients in the present study, regardless of their respective rates of gastric emptying, had some element of autonomic neuropathy involving the parasympathetic or sympathetic nervous systems.

Hyperglycaemia seemed to have no influence on the rate of gastric emptying in this study, as there was no correlation between the fasting blood glucose concentration at the time of study and the gastric emptying half time. In fact, the shortest gastric emptying half time was seen in the patient (KA) who had the highest blood glucose value. A number of investigations have shown that acute hyperglycaemia delays gastric emptying of a liquid meal in healthy, non-diabetic subjects as well as in type I (insulin dependent) diabetic patients. ${ }^{38-40}$ Hyperglycaemia has also been shown to increase the frequency of pyloric contractions and inhibit antral contractions in non-diabetic subjects. ${ }^{41}$ The influence of hyperglycaemia on gastric emptying in a diabetic population has not been examined. The results of our investigation suggest that the neurohumoral controls regulating the interplay between blood glucose concentrations and the rate of gastric emptying are disordered in diabetes.

These findings have relevance to the management of patients with insulin dependent diabetes. Conventional insulin treatment anticipates that ingestion of a nutrient meal is followed by an orderly and predictable rise in postprandial blood glucose. The dosage of exogenously administered insulin is tailored to meet this rise in blood glucose values. Hypothetically, accelerated gastric emptying, as exemplified by some patients in this study, should be accompanied by a premature and unanticipated rise in blood glucose concentrations. This event would consequently be followed by the tardy and untimely absorption of insulin into the blood stream. Hence, the present study shows the importance of gastric emptying in the maintenance of glycaemic control in a diabetic patient.

The pathophysiology of rapid gastric emptying in diabetes mellitus remains obscure. However, one investigation of diabetic subjects with neuropathy showed that rapid gastric emptying of a liquid meal was associated with higher intragastric pressures measured during air insufflation. ${ }^{6}$ It was suggested that the acceleration of gastric emptying was due to impaired gastric accommodation to distension. This phenomenon is supported by observations seen in streptozotocin treated diabetic rodents who characteristically show accelerated gastric emptying of a solid meal shortly after induction of diabetes. ${ }^{42}$ Strips of muscle excised from the gastric body of these diabetic animals and placed in organ baths show an impaired relaxation response when the intramural myenteric nerves are subjected to electrical field stimulation. Contraction responses, mediated by excitatory cholinergic nerves, are intact. These observations indicate that accelerated gastric emptying in diabetic 
rodents is associated with impaired noncholinergic 'inhibitory' neuromuscular transmission involving the gastric myenteric plexus. Whether the same mechanism is a factor in human diabetes mellitus must await further investigative scrutiny.

The authors are indebted to Ms Brenda Edwards for her secretarial expertise in the preparation of this manuscript.

This investigation was supported by a grant (R29 DK38863-

05) from the National Institutes of Health.

Study results based on the first 11 diabetic patients were previously published in abstract form in Gastroenterology 1990 98: A378.

1 Feldman M, Schiller LR. Disorders of gastrointestinal motility associated with diabetes mellitus. Ann Intern Med motility associated

2 Campbell A, Conway H. Gastric retention and hypoglycemia in diabetes. Scott Med F 1960; 5: 167-8

3 Wooten RL, Meriwether TW III. Diabetic gastric atony: a clinical study. $¥ A M A 1961$; 176: 1082-7.

4 Gupta KK, Hegde KP, Lal R. Diabetic gastric neuropathy with acute hypoglycaemic attacks. F Indian Med Assoc 1971; 57: 258-9.

5 Phillips WT, Schwartz JG, McMahan CA. Rapid gastric emptying of an oral glucose solution in type II diabetic patients. F Nucl Med 1992; 33: 1496-500

6 Oliveira RB, Troncon LEA, Meneghelli UG, Dantas RO, Godoy RA. Gastric accommodation to distension and early gastric emptying in diabetics with neuropathy. Braz early gastric emptying in diabetic

7 Horowitz M, Harding PE, Maddox A, Maddern GJ, Collins PJ, Chatterton BE, et al. Gastric and esophageal emptying in insulin-dependent diabetes mellitus. $\mathcal{F}$ Gastroentero Hepatol 1986; 1: 97-113.

8 Campbell IW, Heading RC, Tothill P, Buist TAS, Ewing DJ, Clarke BF. Gastric emptying in diabetic autonomic neuropathy. Gut 1977; 18: 462-7.

9 Keshavarzian A, Iber FL, Vaeth J. Gastric emptying in patients with insulin-requiring diabetes mellitus. $A m \mathcal{F}$ Gastroenterol 1987; 82: 29-35.

10 Horowitz M, Harding PE, Maddox AF, Wishart JM, Akkermans LMA, Chatterton BE, Shearman DJC. Gastric and esphageal emptying in patients with type II (non-insulin-dependent) diabetes mellitus. Diabetologia 1989; 32: 151-9.

11 Loo FD, Palmer DW, Soergel KH, Kalbfleisch JH, Wood CM. Gastric emptying in patients with diabetes mellitus. CM. Gastric emptying in patients
Gastroenterology 1984; 86: 485-94.

12 Lipsitz LA. Orthostatic hypotension in the elderly. $N$ Engl $\mathscr{f}$ Med 1989; 321: 952-7

13 Pfeifer MA, Peterson H. Cardiovascular autonomic neuropathy. In: Dyck PJ, Thomas PK, Asbury AK, Winegrad AI, Porte D, eds. Diabetic neuropathy. Philadelphia, PA W B Saunders Company, 1987: 122-33.

14 Smith SA. Reduced sinus arrhythmia in diabetic autonomic neuropathy: diagnostic value of an age-related normal range. $B M F$ 1982; 285: 1599-601.

15 Elashoff JD, Reedy TJ, Meyer JH. Analysis of gastric emptying data. Gastroenterology 1982; 83: 1306-12.

16 SAS Institute. Statistical analysis system (SAS). Cary, North SAS Institute. Statistical analysis system (SAS). Cary, North
Carolina: SAS Institute Incorporated (procedure NLIN).

17 Ott L. An introduction to statistical methods and data analysis. Ott L. An introduction to statistical methods and data analysis.
Boston: Kent Publishing Company, 1988; chap 10: section 5 .

18 Fox S, Behar J. Pathogenesis of diabetic gastroparesis: a pharmacologic study. Gastroenterology 1980; 78: 757-63.

19 Feldman M, Corbett DB, Ramsey EJ, Walsh JH, Richardson CT. Abnormal gastric function in longstanding, insulin-dependent diabetic patients. Gastroenterology 1979; 77: 12-7.
20 Yoshida MM, Schuffler MD, Sumi SM. There are no morphologic abnormalities of the gastric wall or abdominal vagus in patients with diabetic gastroparesis. Gastroenterology 1988; 94: 907-14.

21 Talman WT, Andreasen K, Calvin J, Eversman-Johanns S. Cholecystokinin in nucleus tractus solitarii modulates Cholecystokinin in nucleus tractus solitari modulates
tonic and phasic gastric pressure. Am f Physiol 1991; 261: tonic and $217-22$.

22 Feng H-S, Lynn RB, Han J, Brooks FP. Gastric effects of TRH analogue and bicuculinne injected into dorsal motor vagal nucleus in cats. Am F Physiol 1990; 259: G321-6.

23 Granneman JG, Stricker EM. Food intake and gastric emptying in rats with streptozotocin-induced diabetes. Am $\mathcal{F}$ Physiol 1984; 247: R1054-61.

24 Edens NK, Friedman MI. Satiating effect of fat in diabetic rats: gastrointestinal and postabsorptive factors. $\mathrm{Am} \mathcal{F}$ Physiol 1988; 255: R123-7.

25 Nowak TV, Roza AM, Weisbruch JP, Brosnan MR Accelerated gastric emptying in diabetic rodents: effect of insulin treatment and pancreas transplantation. $f$ Lab Clin Med 1994; 123: 110-6.

26 Raybould HE, Taché Y. Cholecystokinin inhibits gastric motility and emptying via a capsaicin-sensitive vagal pathway in rats. Am 7 Physiol 1988; 255: G242-6.

27 Forster ER, Green T, Elliot M, Bremner A, Dockray GJ Gastric emptying in rats: role of afferent neurons and cholecystokinin. Am $\mathcal{F}$ Physiol 1990; 258: G522-56.

28 Nowak TV, Castelaz C, Ramaswamy K, Weisbruch JP. Impaired rodent vagal nerve sodium-potassium ATPase $\left(\mathrm{Na}^{+}-\mathrm{K}^{+}\right.$-ATPase) activity in streptozotocin diabetes. Gastroenterology 1990; 99: 1223.

29 Schade RR, Dugas MC, Lhotsky DM, Gavaler JS, Van Thiel DH. Effect of metoclopramide on gastric liquid emptying in patients with diabetic gastroparesis. Dig Dis Sci 1985; 30: 10-5.

30 Brown-Cartwright D, Smith HJ, Feldman M. Gastric emptying of an indigestible solid in patients with endemptying of an indigestible solid in patients with end-
stage renal disease on continuous ambulatory peritoneal stage renal disease on continuous ambulato
dialysis. Gastroenterology 1988; 95: 49-51.

31 McNamee PT, Moore GW, McGeown MG, Doherty CC Collins BJ. Gastric emptying in chronic renal failure. $B M \mathcal{F}$ 1985; 291: $310-1$.

32 Freeman JG, Gobden I, Heaton A, Keir M. Gastric emptying in chronic renal failure. $B M \mathcal{F} 1985 ; 291: 1048$.

33 Wright RA, Clemente $R$, Wathen $R$. Gastric emptying in patients with chronic renal failure receiving hemodialysis. Arch Intern Med 1984; 144: 495-596.

34 Soffer EE, Geva B, Avni Y, Bar-Meir S. Gastric emptying in chronic renal failure patients on hemodialysis. chronic renal failure patient
Gastroenterology 1985; 88: 1592.

35 Pfeifer MA, Weinberg CR, Cook DL, Reenan A, Halter JB, Ensinck JW, et al. Autonomic neural dysfunction in recently diagnosed diabetic subjects. Diabetes Care 1984, recently $447-53$.

36 Wheeler T, Watkins PJ. Cardiac denervation in diabetes. $B M F$ 1973; 4: 584-6.

37 Pfeifer MA, Cook D, Brodsky J, Tice D, Reenan A, Swedine S, et al. Quantitative evaluation of cardiac parasympathetic activity in normal and diabetic man. Diabetes 1982; 31: 339-45.

38 MacGregor IL, Gueller R, Watts HD, Meyer JH. The effect of acute hyperglycemia on gastric emptying in man. Gastroenterology 1976; 70: 190-6.

39 Aylett P. Gastric emptying and change of blood glucose level, as affected by glucagon and insulin. Clin Sci 1962; 22: $171-8$.

40 Fraser RJ, Horowitz M, Maddox AF, Harding PE, Chatterton BE, Dent J. Hyperglycemia slows gastric emptying in type I (insulin-dependent) diabetes mellitus. Diabetologia 1990; 33: 675-80.

41 Fraser R, Horowitz M, Dent J. Hyperglycemia stimulates pyloric motility in normal subjects. Gut 1991; 32: 475-8

42 Nowak TV, Brosnan M. Abnormal gastric emptying and impaired inhibitory neuromuscular transmission in diabetic rodent stomach. Fournal of Gastrointestinal Motility 1993; 5: 208. 